\title{
An Ice Storage Tank Modelica Model: Implementation and Validation
}

\author{
Guowen $\mathrm{Li}^{1} \quad$ Yangyang Fu$^{1} \quad$ Amanda Pertzborn ${ }^{2}$ Jin Wen $^{3}$ Zheng O'Neill ${ }^{1}$ \\ ${ }^{1}$ J. Mike Walker '66 Department of Mechanical Engineering, Texas A\&M University, College \\ Station, TX \\ \{guowenli, yangyang.fu, zoneill\}@tamu.edu \\ ${ }^{2}$ National Institute of Standards and Technology, Gaithersburg, MD \\ \{amanda.pertzborn@nist.gov\} \\ ${ }^{3}$ Department of Civil, Architectural and Environmental Engineering, Drexel University, \\ Philadelphia, PA \\ $\{$ jinwen@drexel.edu $\}$
}

\begin{abstract}
Energy storage systems have been gaining attention as a means of load management in grid-interactive efficient buildings. This study investigated the physics of the ice storage tank (IST) and implemented an IST model in Modelica. The developed IST Modelica model was compared with a similar model in EnergyPlus and was validated against experimental data from a testbed at the National Institute of Standards and Technology. Three statistical performance metrics were used to quantify the accuracy of the IST model. Validation results $(\mathrm{CV}(\mathrm{RMSE}) \leq 10.20 \%, \mathrm{NMBE} \leq 0.44 \%)$ show that the proposed model has a good prediction accuracy according to ASHRAE Guideline 14.
\end{abstract}

Keywords: Ice storage tank, Modelica modeling, Model validation

\section{Introduction}

Ice thermal storage systems have been proven to be effective in reducing the cost of energy for operating buildings by shifting cooling demand from on-peak periods with high electricity prices to off-peak periods with lower electricity prices. The ice storage tank (IST) is a key component in an ice thermal storage system. By applying proper control strategies to the IST, research studies have shown significant cost savings including energy costs and demand reduction costs (e.g., $10 \%$ to $55 \%$ ), which makes IST an attractive financial option for buildings (Braun 1990; Henze 2003; Candanedo 2013). Control-oriented modeling and simulation is an effective way to evaluate the system performance under different control strategies. Jekel (1991) created a model of a static ice-on-coil IST based on basic heat transfer relationships and analysis; the author used TRNSYS (Beckman 1994) to model a variable flow air-conditioner system connected with the IST. Both the charging and discharging periods of the tank operation were modeled and compared with manufacturers' data (Calmac ice tank model 1190 with working fluid of $25 \%$ ethylene glycol). The prediction errors for the charging and discharging period were within $12 \%$ and $10 \%$ of the manufacturer's performance data, respectively. Ihm et al. (2004) developed an ice-based thermal storage model for EnergyPlus. This IST model uses the building load and system thermodynamic models for two direct ice systems (i.e. ice-on-coil external melt and ice harvester) and one indirect ice system (i.e. ice-oncoil internal melt). For the external (or internal) melt thermal storage tank, the brine flowing through coils charges and discharges the tank on the outside (or inside) of the coils. The thermal storage model systems were integrated as part of the EnergyPlus cooling plant components. Candanedo et al. (2013) numerically investigated the impact of different control strategies for a simplified ice storage system developed in EnergyPlus.

In terms of building energy and control system modeling, traditional building energy simulators, including TRNSYS and EnergyPlus, have the following limitations. First, these traditional simulation programs intertwine model equations and numerical solvers in their source code. The lack of separation between model equations, data, and solvers makes it hard for their models to support some use cases, especially when different control strategies and designs are involved (Wetter 2009). Second, some platforms, which are inherently designed for a steady-state simulation, are not suitable for evaluating the system dynamics, and the semantics of their control modules have little in common with how actual control works (Fu 2019). For example, EnergyPlus does not model local controllers (e.g., proportional-integral (PI) controller) for a building energy system. Additionally, the dead band and waiting time commonly used in building controls are not considered in EnergyPlus. The idealization of control makes it difficult to investigate, implement and verify actual control strategies in simulation (Wetter 2011; Fu 2018).

\footnotetext{
Certain commercial equipment, instruments, or materials are identified in this paper in order to specify the experimental procedure adequately. Such identification is not intended to imply recommendation or endorsement by NIST, nor is it intended to imply that the materials or equipment identified are necessarily the best available for the purpose.
} 
To address these problems, the equation-based modeling language Modelica (Mattsson 1998) has been utilized to model and simulate building energy and control systems. The open-source Modelica Buildings Library (MBL) was developed by Lawrence Berkeley National Laboratory for typical building energy and control system modeling and simulation (Wetter 2014). However, the latest release of the MBL does not support the modeling of ice storage tank systems due to the lack of ice tank models.

This study implemented and validated an IST Modelica model based on MBL to support control-oriented studies, which could extend MBL to enable ice storage systems modeling and simulation. The rest of this paper is organized as follows: Section 2 describes the mathematical equations of the IST model and three statistical metrics to quantify and evaluate the model accuracy. Section 3 discusses how the IST model was implemented in the Modelica environment using the MBL. Section 4 validates the implemented IST model in Modelica against a similar model in EnergyPlus and experimental data from the National Institute of Standards and Technology (NIST). The final section is the conclusion.

\section{Methodology}

\subsection{IST Mathematical Model}

The mathematical model of the IST is based on the EnergyPlus model (Strand 1992) presented in Eqs. (1) to (8). The detailed IST model allows the users to model more closely specific manufacturers' ice storage units due to the use of curve fits. In section 4, the IST model was validated against an actual ice tank at NIST which is the type of ice-on-coil internal melt. The IST has three modes: a dormant mode when the storage is not engaged in operation, a discharging mode when the storage discharges cooling energy to the warm brine, and a charging mode when the storage is charged with the cold brine. When the tank is dormant, there is no fluid passing through the tank and the outlet temperature is considered to be equal to the inlet temperature. Details about the discharging mode and charging mode are shown.

- Discharging Mode

$$
\begin{aligned}
& \dot{q}^{*} \times \Delta t= \\
& d_{1}+d_{2}\left(1-P_{c h}\right)+d_{3}\left(1-P_{c h}\right)^{2}+ \\
& {\left[d_{4}+d_{5}\left(1-P_{c h}\right)+d_{6}\left(1-P_{c h}\right)^{2}\right] \Delta T_{l m}^{*}} \\
& \dot{q}^{*}=\frac{\dot{q}}{Q_{\text {sto }}} \\
& \dot{q}=\dot{m} c_{p}\left(T_{\text {out }}-T_{\text {in }}\right) \\
& \Delta T_{\text {lm }}^{*}=\frac{\Delta T_{\text {lm }}}{\Delta T_{\text {nom }}} \\
& \Delta T_{\text {lm }}=\frac{\Delta T_{1}-\Delta T_{2}}{\ln \left(\frac{\Delta T_{1}}{\Delta T_{2}}\right)}=\frac{T_{\text {in }}-T_{\text {out }}}{\ln \left(\frac{T_{\text {in }}-T_{\text {fre }}}{T_{\text {out }}-T_{\text {fre }}}\right)}
\end{aligned}
$$

where, $\dot{q}^{*}$ is the normalized instantaneous heat transfer rate between the brine and the ice in the tank; $\Delta t$ is the time step of the operation data used in the curve fitting for discharging coefficients $d_{1}$ to $d_{6} ; P_{c h}$ is the fraction charged; $\Delta T_{l m}$ is the logarithmic mean temperature difference (LMTD); $\Delta T_{l m}^{*}$ is the LMTD between the inlet and outlet temperature of the tank normalized by a nominal temperature difference, $\Delta T_{n o m}$. Physically, $\dot{q}^{*}$ is defined as the ratio of the instantaneous heat transfer rate $\dot{q}$ to the total latent storage capacity $Q_{s t o} ; \dot{q}$ is negative when the tank is discharged. $T_{i n}$ is the tank inlet temperature, $T_{\text {out }}$ is the tank outlet temperature, and $T_{\text {fre }}$ is the freezing temperature of water or the latent energy storage material.

Eq. (5) is not numerically robust due to singularities that occur in the following scenarios: 1) $\Delta T_{1}=\Delta T_{2}$, which causes a denominator of zero; 2) $\Delta T_{1}=0$ or $\Delta T_{2}=0$, which violates the logarithm function; 3) $\Delta T_{1}$ and $\Delta T_{2}$ have different signs. For a robust implementation of the LMTD calculation in the Modelica numerical environment, Eq. (5) is smoothed over different regions as shown in Eq. (5.1) to Eq. (5.5). The function $f_{\text {smoothMax }}\left(y, y_{\text {lim }}\right)$ provides a continuously differentiable approximation for the variable $y$, which can be no less than the limiting value $y_{\text {lim }}$. The function $f_{\text {smoothmin }}\left(y, y_{\text {lim }}\right)$ limits the variable $y$ to be no larger than $y_{\text {lim }}$, where $\Delta y=y-y_{\text {lim }}$, and $\delta$ is used for regularization. When $|\Delta y|<\delta$, a second order polynomial function is used to create a smooth transition from $y$ to $y_{\text {lim }}$. The smoothed functions not only help avoid the occurrence of zero in the denominator, but also ensure the continuity and differentiability of the simulated data.

$$
\begin{aligned}
& \Delta T_{1}=f_{\text {smoothMax }}\left(T_{\text {in }}-T_{\text {fre }}, T_{\text {lim }}\right) \\
& \Delta T_{2}=f_{\text {smoothMax }}\left(T_{\text {out }}-T_{\text {fre }}, T_{\text {lim }}\right) \\
& \Delta T_{\text {lm }}=f_{\text {smoothMin }}\left(\frac{\Delta T_{1}-\Delta T_{2}}{\ln \left(\frac{\Delta T_{1}}{\Delta T_{2}}\right)}, \Delta T_{\text {lim }}\right)
\end{aligned}
$$

$f_{\text {smoothMax }}\left(y, y_{\text {lim }}\right)$

$$
\begin{aligned}
& =\left\{\begin{array}{lr}
y, & \left(y>y_{\text {lim }}+\delta\right) \\
y_{\text {lim }}, & \left(y<y_{\text {lim }}-\delta\right) \\
\frac{y+y_{\text {lim }},}{2}, & (|\Delta y|=\delta) \\
\frac{\Delta y^{2}\left(3-\frac{\Delta y^{2}}{\delta^{2}}\right)}{4}+\frac{y+y_{\text {lim }}}{2}, & (|\Delta y|<\delta)
\end{array}\right. \\
& f_{\text {smoothMin }}\left(y, y_{\text {lim }}\right) \\
& =\left\{\begin{array}{lr}
y_{\text {lim }}, & \left(y>y_{\text {lim }}+\delta\right) \\
y, & \left(y<y_{\text {lim }}-\delta\right) \\
\frac{y+y_{\text {lim }}}{2}, & (|\Delta y|=\delta) \\
\frac{\frac{\Delta y^{2}}{\delta}\left(\frac{\Delta y^{2}}{\delta^{2}}-3\right)}{4}+\frac{y+y_{\text {lim }}}{2}, & (|\Delta y|<\delta)
\end{array}\right.
\end{aligned}
$$

- Charging Mode 
When the thermal tank is being charged, the charging heat transfer is calculated by Eq. (6). The constant parameters $c_{1} \sim c_{6}$ are charging coefficients.

$$
\begin{aligned}
& \dot{q}^{*} \times \Delta t= \\
& c_{1}+c_{2} P_{c h}+c_{3} P_{c h}{ }^{2}+ \\
& {\left[c_{4}+c_{5} P_{c h}+c_{6} P_{c h}{ }^{2}\right] \Delta T_{l m}^{*}}
\end{aligned}
$$

For both discharging mode and charging mode, the mass of ice in the tank is calculated by Eqs. (7) and (8), where $S O C$ is the state of charge that indicates the mass ratio $(0 \%-100 \%)$ of ice in the tank, $S O C^{\prime}$ is the derivative of $S O C, H_{f}$ is the latent heat of fusion for water at $0{ }^{\circ} \mathrm{C}$, $m_{\text {ice }}$ is the mass of ice in the tank, $m_{\text {ice, } \max }$ is the maximum ice capacity of the tank, and $\dot{m}$ is the mass flow rate of the fluid.

$$
\begin{aligned}
& S O C^{\prime}=\frac{\dot{m} c_{p}\left(T_{\text {out }}-T_{\text {in }}\right)}{m_{\text {ice, } \max } H_{f}} \\
& S O C=\frac{m_{\text {ice }}}{m_{\text {ice, } \max }}
\end{aligned}
$$

\subsection{Validation Metrics}

To evaluate the accuracy of the proposed model, three statistical metrics are applied: Coefficient of Variation of Root Mean Square Error (CV(RMSE)), the coefficient of determination $\left(\mathrm{R}^{2}\right)$, and the Normalized Mean Bias Error (NMBE). These metrics are defined in Eq. (9) to Eq. (12).

$$
\begin{aligned}
& R M S E=\sqrt{\frac{\sum_{i=1}^{n}\left(Y_{i}-\hat{Y}_{i}\right)^{2}}{n},} \\
& C V(R M S E)=\frac{R M S E}{\bar{Y}_{i}}, \\
& R^{2}=1-\frac{\sum_{i=1}^{n}\left(Y_{i}-\hat{Y}_{i}\right)^{2}}{\sum_{i=1}^{n}\left(Y_{i}-\bar{Y}_{i}\right)^{2}} \\
& N M B E=\frac{\sum_{i=1}^{n}\left(Y_{i}-\hat{Y}_{i}\right)^{2}}{(n-p) \times \bar{Y}_{i}},
\end{aligned}
$$

where, $Y_{i}$ is the measured data, $\hat{Y}_{i}$ is the predicted data, $n$ is the number of data points, $\bar{Y}_{i}$ is the mean value of the measured data, $p$ is the number of parameters in the numerical model.

According to ASHRAE Guideline 14 (ASHRAE 2014), the predicted model shall have an NMBE up to $5 \%$ and a CV(RMSE) up to $15 \%$ using monthly calibration data. If hourly calibration data are used, these requirements shall be $10 \%$ and $30 \%$, respectively.

\section{Modelica Modeling}

\subsection{Model Description}

The IST Modelica model contains four key components as presented in Figure 1: LMTD calculator, heat flow rate calculator, storage mode selector, and outlet temperature controller. The storage mode selector sends the mode signal (discharging, charging, dormant) to the LMTD calculator and the outlet temperature controller that controls the outlet temperature to the setpoint. The heat flow rate calculator outputs the SOC and ice mass. Table 1 summarizes the key components in the IST Modelica model.

Table 1. Description of the IST Modelica model.

\begin{tabular}{ll} 
Components & Model Description \\
\hline LMTD Calculator & $\begin{array}{l}\text { LMTD algorithm with } \\
\text { smooth functions } \\
\text { Pelynomial coefficients of } \\
\text { Calculator }\end{array}$ \\
curve fitting data \\
Storage Mode & Discharging, charging, \\
selector & dormant mode \\
Outlet Temp & PI control for the main valve \\
Controller & and bypass valve \\
\hline
\end{tabular}

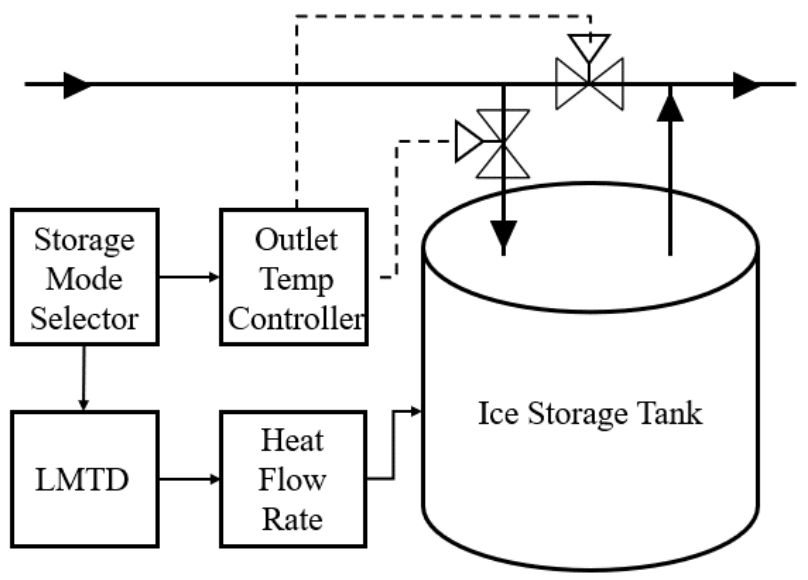

Figure 1. Schematic diagram of the IST model.

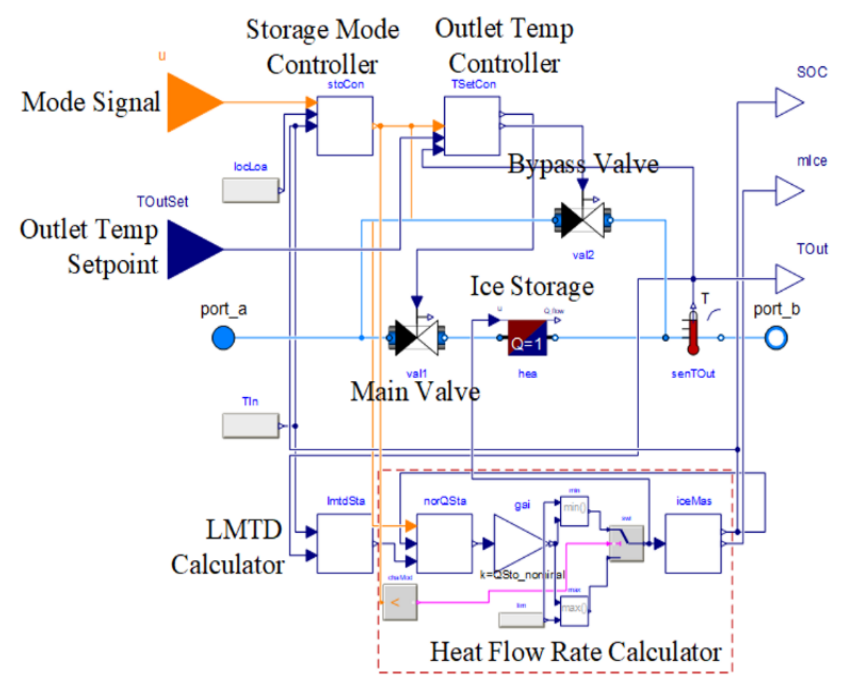

Figure 2. Modelica model of the ice storage tank.

\subsection{Model Components}

Figure 2 presents the detailed components inside the IST Modelica model; details of each component are described below. 


\section{- LMTD Calculator}

LMTD is the key intermediate variable that determines the calculation process of the whole model, which is calculated by Eqs. (5.1) - (5.5).

\section{- Heat Flow Rate Calculator}

The heat flow rate is calculated by Eq. (1) and Eq. (6) for discharging and charging mode, respectively. When the tank is dormant, the heat flow rate is assumed to be zero.

\section{- $\quad$ Storage Mode Selector}

The storage mode selector determines the operating mode of the tank (i.e., dormant, discharging, or charging modes) in response to measured system states such as $\mathrm{SOC}$, the flow rate, and the inlet temperature of the coolant.

The state diagram of the storage mode selector is shown in Figure 3. If the mass flow rate is greater than the minimum flow rate, the inlet temperature is greater than the freezing temperature of water plus a temperature tolerance $\left(d T_{i f, \min }\right)$, and SOC is greater than a discharging tolerance, then the ice storage tank is in the discharging mode. If the mass flow rate is greater than the minimum flow rate, the inlet temperature is less than the freezing temperature of water minus a temperature tolerance, and SOC is less than a charging tolerance, then the ice storage tank is in the charging mode. Otherwise, the tank is dormant and bypassed. Figure 4 shows the state graph diagram implemented in Modelica, which has four input signals and one output signal, the storage mode.

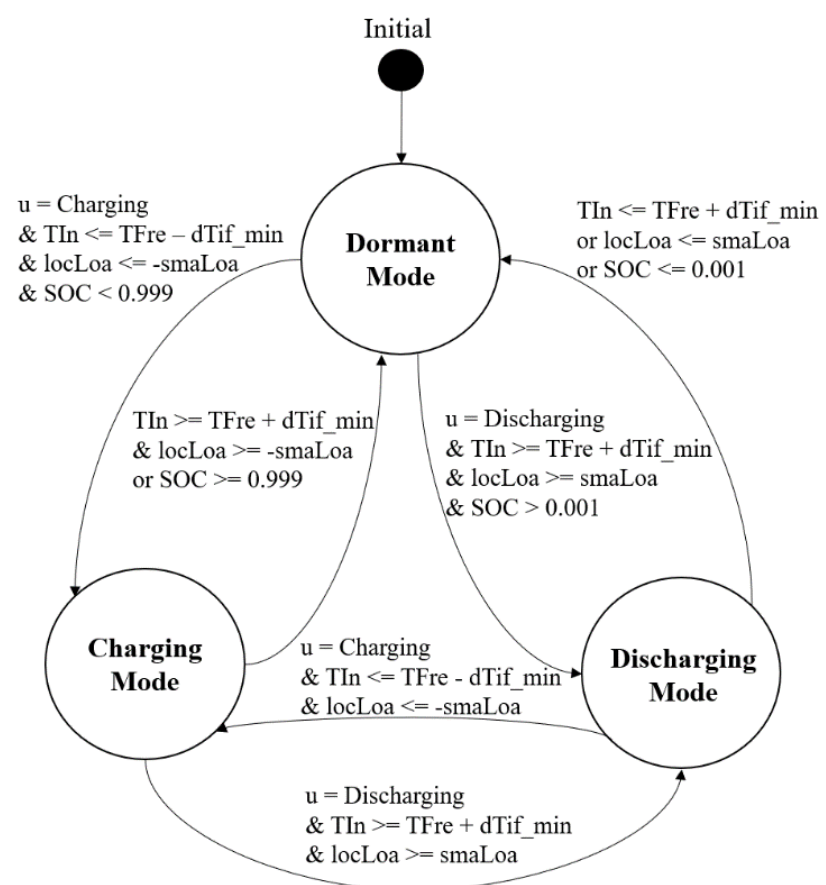

Figure 3. State diagram of the storage mode selector.

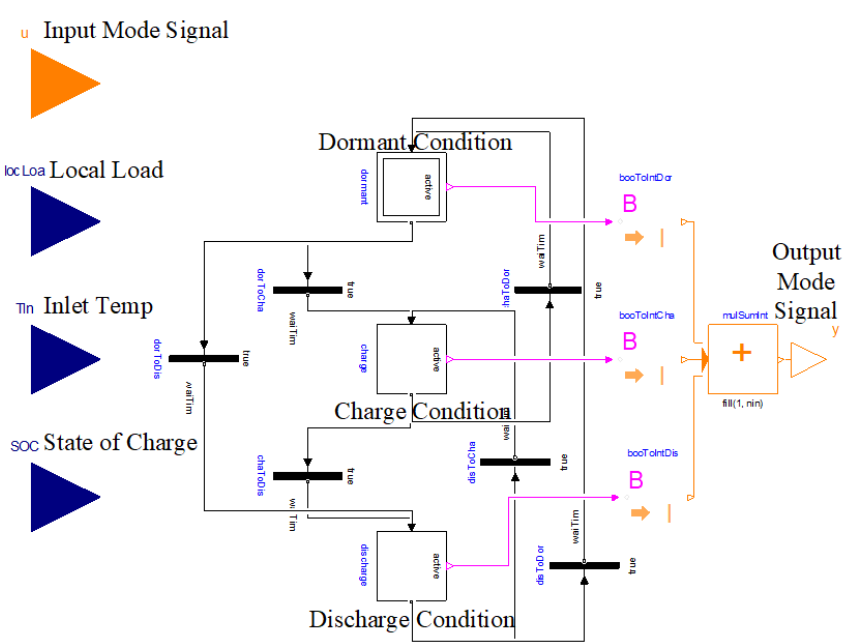

Figure 4. Modelica diagram of the storage mode selector.

- Outlet Temperature Controller

The IST outlet temperature is maintained at its setpoint by adjusting the bypass valve position through a built-in PI controller. The control values and diagram of the outlet temperature controller are shown in Table 2 and Figure 5, where $\mathrm{K} 1$ is the opening value of the main valve, $K 2$ is the opening value of the bypass valve, and $u_{P I}$ is the output value of a built-in PI controller. If the tank is dormant, the main valve will be closed $(\mathrm{K} 1=0)$ and the bypass valve will be fully open $(\mathrm{K} 2=1)$. If the tank is charged, the main valve will be fully open $(\mathrm{K} 1=1)$ and the bypass valve will be closed $(\mathrm{K} 2=0)$. If the tank is discharged, the PI controller will adjust the main valve and the bypass valve to meet the outlet temperature setpoint ( $\mathrm{K} 1=1-u_{P I}$, $\left.\mathrm{K} 2=u_{P I}\right)$.

Table 2. Control values of the outlet temperature controller.

\begin{tabular}{llll}
\hline Mode & Dormant & Charging & Discharging \\
\hline Main & Off & On & On \\
Valve & $(\mathrm{K} 1=0)$ & $(\mathrm{K} 1=1)$ & $\left(\mathrm{K} 1=1-u_{P I}\right)$ \\
Bypass & On & Off & On \\
Valve & $(\mathrm{K} 2=1)$ & $(\mathrm{K} 2=0)$ & $\left(\mathrm{K} 2=u_{P I}\right)$ \\
\hline
\end{tabular}

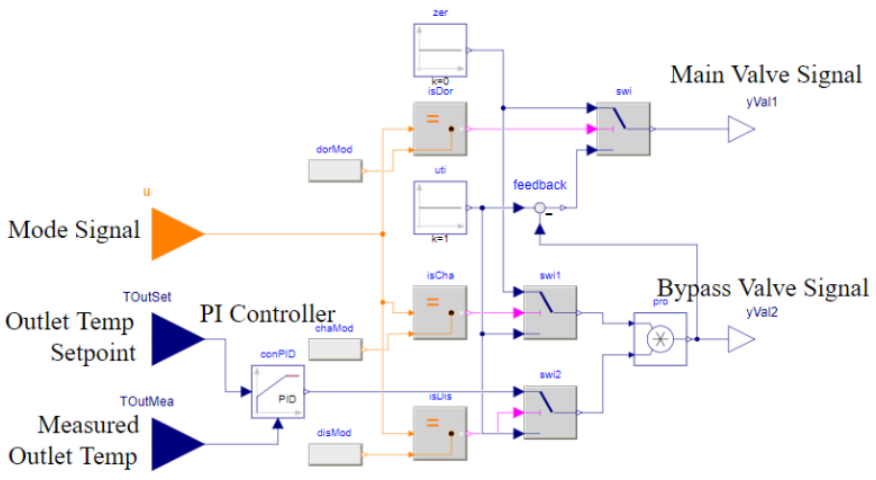

Figure 5. Modelica diagram of the outlet temperature controller. 


\section{Comparison and Validation}

This section presents the comparison and validation of the IST Modelica model against two data sources: 1) a similar model in EnergyPlus and 2) measurement data from NIST. Three accuracy metrics are presented.

\subsection{Modelica Model vs. EnergyPlus Model}

We selected a built-in IST model in an EnergyPlus ice tank example file that is based on the same mathematical model (Strand 1992) presented in Eqs. (1) to (8). Table 3 lists the details of the EnergyPlus model with modified parameters (cooling capacity, polynomial coefficients of charging curve data, and medium type). The IST EnergyPlus model was simulated for about 8 hours (from 10 a.m. to 6 p.m.) of discharging operation and 2 hours (from 0 a.m. to 2 a.m.) of charging operation on July $21^{\text {st }}$ using typical meteorological year (TMY3) weather data. Then the simulated dataset (inlet/outlet temperature of IST, mass flow rate of chilled water, and SOC) from EnergyPlus was exported for use in the Modelica virtual testcase.

Table 3. Description of the IST EnergyPlus model.

\begin{tabular}{|c|c|}
\hline Descriptions & EnergyPlus model \\
\hline Filename & $\begin{array}{l}\text { 5ZoneDetailedIceStorage. } \\
\text { idf }\end{array}$ \\
\hline Weather Data & $\begin{array}{l}\text { Chicago-Midway AP } \\
725340 \text { (TMY3) }\end{array}$ \\
\hline Floor Area & $463.6 \mathrm{~m}^{2}$ \\
\hline $\begin{array}{l}\text { Ice Storage } \\
\text { Capacity }\end{array}$ & $0.05 \mathrm{GJ}$ \\
\hline Number of Story & 1 \\
\hline Number of Zones & 6 \\
\hline $\begin{array}{l}\text { Timestep of } \\
\text { Simulation }\end{array}$ & $1 \mathrm{~min}$ \\
\hline Discharging Curve & $\begin{aligned} d= & {[0.0,0.09,-0.15} \\
& 0.612,-0.324,-0.216]\end{aligned}$ \\
\hline Discharging Time & 10 a.m. to 6 p.m., July $21 \mathrm{st}$ \\
\hline Charging Curve & $c=[0.318,0,0,0,0,0]$ \\
\hline Charging Time & 12a.m. to 2 a.m., July $21^{\text {st }}$ \\
\hline Medium & $\begin{array}{l}30 \% \mathrm{PG} \text { (propylene } \\
\text { glycol) }+70 \% \text { Water }\end{array}$ \\
\hline
\end{tabular}

A virtual testcase was built for the IST Modelica model as presented in Figure 6. The Modelica virtual testcase uses the same IST parameters and inlet conditions (mass flow rate, temperature, etc.) as in EnergyPlus, and compares the tank states (e.g., SOC) and the calculated outlet conditions (e.g., outlet temperature) with those in EnergyPlus. Figure 7 shows the comparison results for SOC and outlet temperature in discharging mode. Figure 8 shows the comparison results in charging mode. The comparisons indicate that the simulated SOC and outlet temperature of the IST Modelica model are in excellent agreement with the outputs of the IST EnergyPlus model.

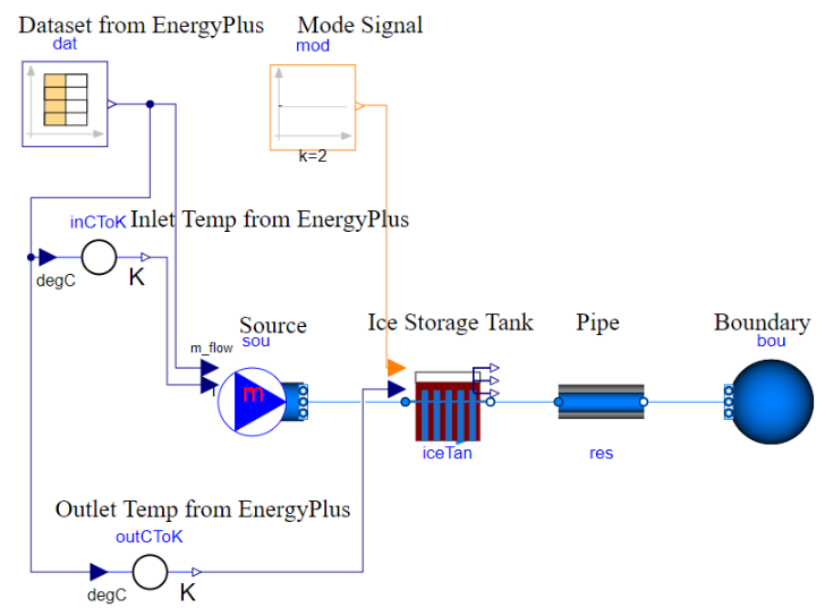

Figure 6. Virtual testcase for the IST Modelica model.

Three statistical metrics (CV(RMSE), NMBE, and $\mathrm{R}^{2}$ ) were calculated to evaluate the accuracy of the prediction, and the results are shown in Table $5 . \mathrm{R}^{2}$ ranges from 0.9311 to $0.9999, \mathrm{CV}(\mathrm{RMSE})$ ranges from $0.00 \%$ to $0.55 \%$, and NMBE is $0.00 \%$ in all scenarios. All three metrics show excellent agreement between the tank performance predictions from the IST Modelica model and the IST EnergyPlus model, which is not a surprise since these two models use the same mathematical equations, though our IST model has more detailed local controls.

\subsection{Simulated Data vs. Measured Data}

In this section, we validate the model prediction with the experimental data obtained from an ice tank testbed at NIST (Pertzborn 2016, Pradhan 2020). Per the manufacturer, the ice storage tank at NIST contains $3,105 \mathrm{~L}$ of water and when fully frozen the ice has a capacity of $274 \mathrm{kWh}$, designed to be discharged over an eight-hour period with an inlet temperature of $10{ }^{\circ} \mathrm{C}$. The chilled water that flows through the IST is a $30 \% \mathrm{PG}$ and $70 \%$ water solution, and the heat exchanger inside the IST is a spiral wound polyethylene tube. The data was collected at a $0.10 \mathrm{~Hz}$ rate. The measured temperature and flow rate of the chilled water are used as the boundary conditions in the Modelica virtual testcase. Table 4 shows the polynomial coefficients for discharging mode and charging mode, which are obtained by regression of the measured data.

Table 4. Polynomial coefficients of curve fitting data.

\begin{tabular}{lcccccc}
\hline Coefficients & $d_{1} / c_{1}$ & $d_{2} / c_{2}$ & $d_{3} / c_{3}$ & $d_{4} / c_{4}$ & $d_{5} / c_{5}$ & $d_{6} / c_{6}$ \\
\hline Discharging & $5.54 \mathrm{E}-5$ & $-1.46 \mathrm{E}-4$ & $9.28 \mathrm{E}-5$ & $1.12 \mathrm{E}-3$ & $-1.10 \mathrm{E}-3$ & $3.01 \mathrm{E}-4$ \\
Charging & $2.00 \mathrm{E}-4$ & 0 & 0 & 0 & 0 & 0 \\
\hline
\end{tabular}


Table 5. Results of statistical metrics (Benchmark: EnergyPlus).

\begin{tabular}{c|ccc|ccc}
\hline \multirow{2}{*}{ Mode } & \multicolumn{3}{|c|}{ SOC } & \multicolumn{3}{c}{ Outlet Temperature } \\
& CV(RMSE) & $R^{2}$ & NMBE & CV(RMSE) & $R^{2}$ & NMBE \\
\hline Discharging & $0.35 \%$ & 0.9999 & $0.00 \%$ & $0.00 \%$ & 0.9999 & $0.00 \%$ \\
Charging & $0.55 \%$ & 0.9986 & $0.00 \%$ & $0.04 \%$ & 0.9311 & $0.00 \%$ \\
\hline
\end{tabular}

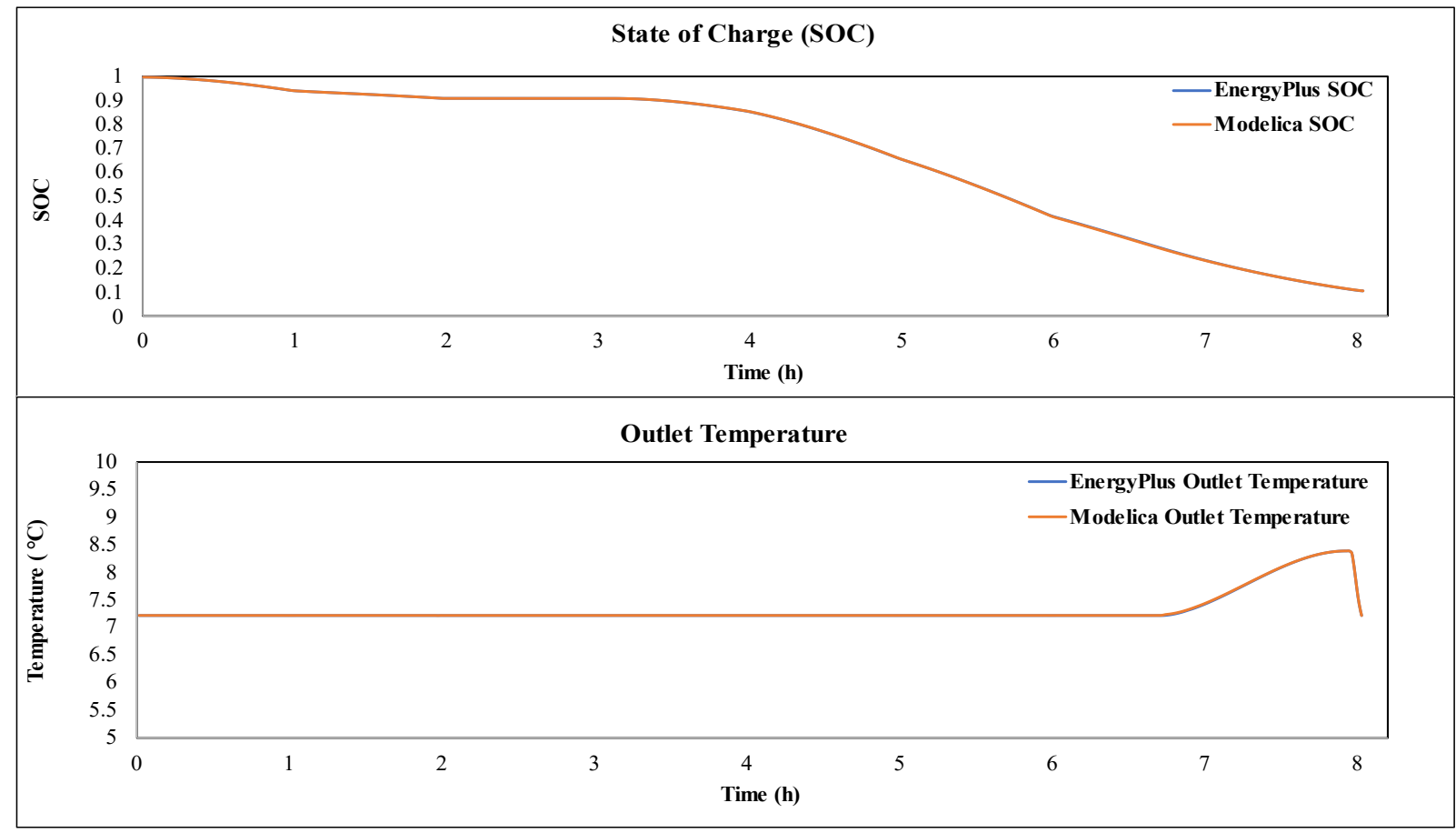

Figure 7. Discharging results comparison of the Modelica model with the EnergyPlus model.



Figure 8. Charging results comparison of the Modelica model with the EnergyPlus model. 
Table 6. Results of statistical metrics (Benchmark: measured data from NIST).

\begin{tabular}{c|ccc|ccc}
\hline $\begin{array}{c}\text { Mode \& } \\
\text { Date }\end{array}$ & CV(RMSE) & $R^{2}$ & NMBE & CV(RMSE) & $R^{2}$ & NMBE \\
\hline $\begin{array}{c}\text { Discharging } \\
(5 / 14 / 2018)\end{array}$ & $7.09 \%$ & 0.9778 & $0.27 \%$ & $0.27 \%$ & 0.8281 & $0.21 \%$ \\
$\begin{array}{c}\text { Charging } \\
(5 / 16 / 2018)\end{array}$ & $10.20 \%$ & 0.9810 & $0.44 \%$ & $0.10 \%$ & 0.8344 & $0.03 \%$ \\
\hline
\end{tabular}

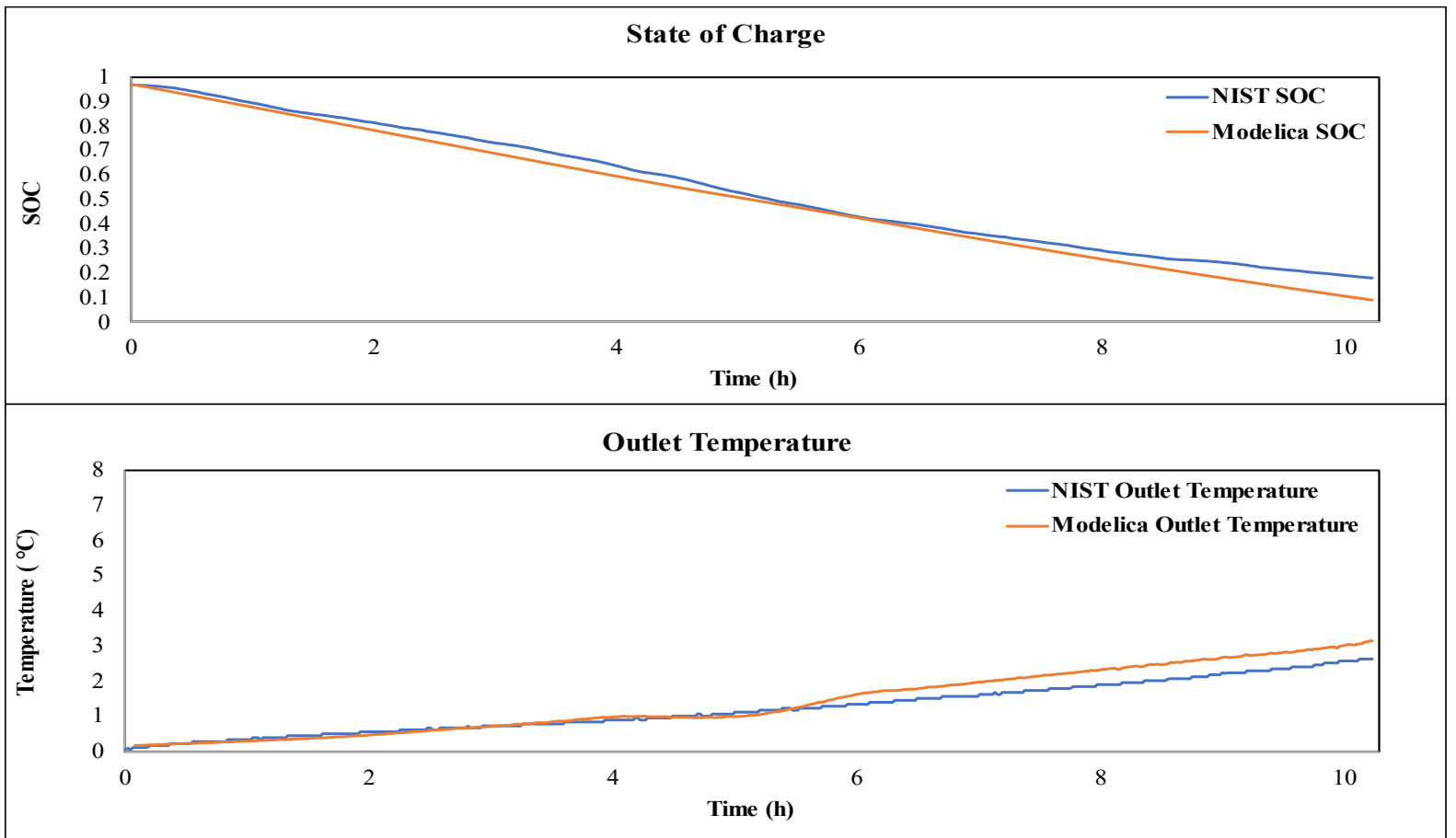

Figure 9. Discharging results comparison of the simulated data with the experimental data on 5/14/2018.

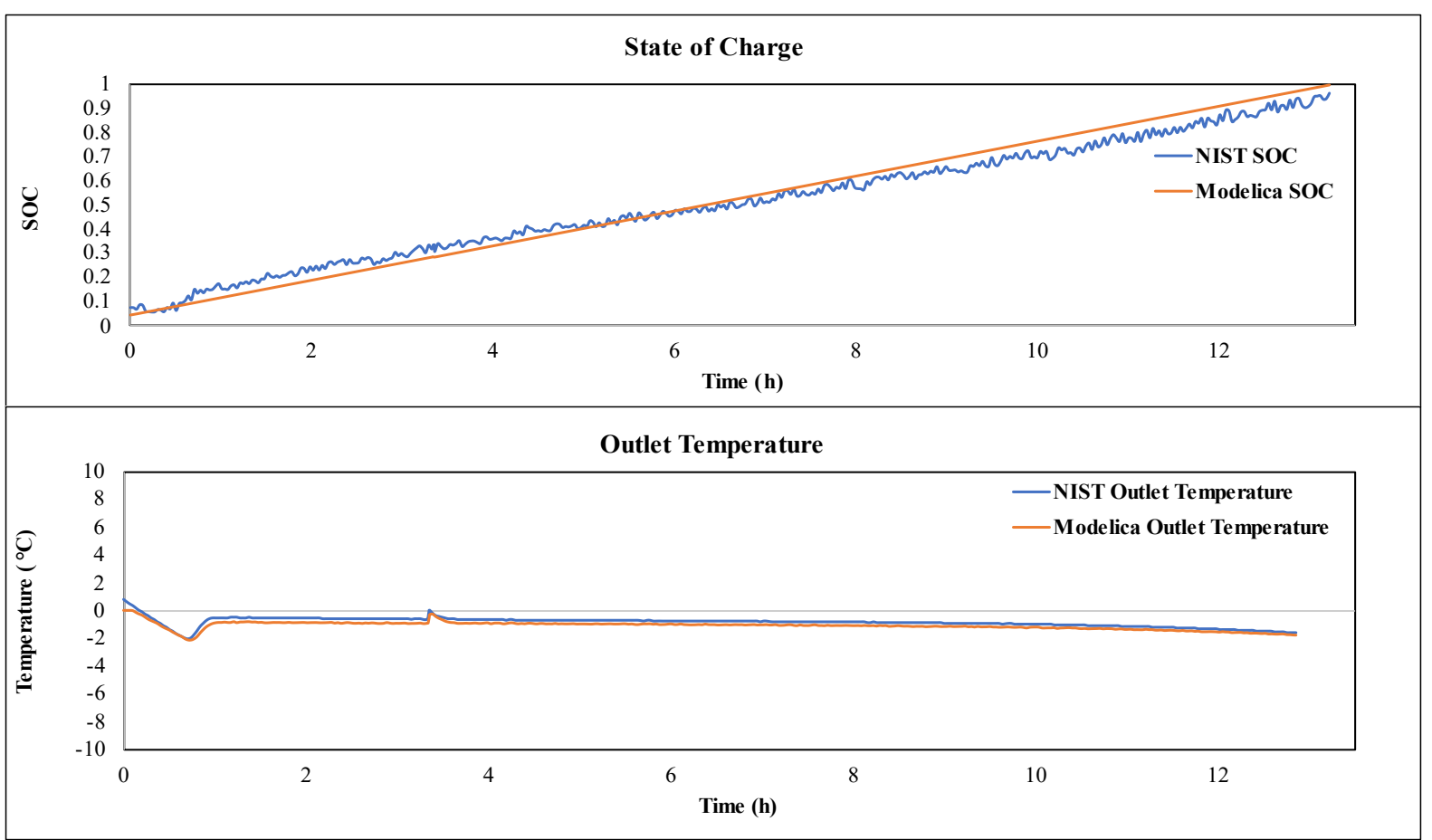

Figure 10. Charging results comparison of the simulated data with the experimental data on 5/16/2018. 
For the discharging mode, the Modelica model is validated using the experimental data on 5/14/2018. For the charging mode, the Modelica model is validated using the experimental data on 5/16/2018. Figure 9 and $P$ Figure 10 show the comparison of simulated results with measured data of the SOC and outlet temperature for two days, respectively.

Table 6 shows the results of three accuracy metrics (CV(RMSE), NMBE, and $\left.\mathrm{R}^{2}\right)$. The $\mathrm{R}^{2}(0.8281-0.9810)$ values are high enough to indicate good agreement between the predictions and the measurement data. ASHRAE Guideline 14 suggests that the predicted model shall have a CV(RMSE) up to $30 \%$ and an NMBE up to $10 \%$ using hourly calibration data (ASHRAE 2014). Comparing the IST Modelica model with the experimental data from NIST, the results of CV(RMSE) $(0.10 \%-10.20 \%)$ and NMBE $(0.03 \%-0.44 \%)$ indicate that the IST Modelica model can provide good accuracy according to ASHRAE Guideline 14.

\section{Conclusion}

This study implemented an ice storage tank model based on the Modelica Buildings Library. The model was then compared to and validated against the EnergyPlus model and the measured data from a real ice tank system, respectively. The validation results quantified by three statistical metrics show a good prediction accuracy. In the future, the proposed IST Modelica model will be tested on system-level control evaluations and be used for load side management for better building-to-grid integration.

\section{Acknowledgements}

The research reported in this paper was partially supported by the Building Technologies Office at the U.S. Department of Energy through the Emerging Technologies program under award number DEEE0009153.

\section{Nomenclature}

\section{Abbreviations:}

ASHRAE: American Society of Heating, Refrigerating and Air-Conditioning Engineers

CV(RMSE): Coefficient of Variation of Root Mean Square Error

IST: Ice Storage Tank

LMTD: Logarithmic Mean Temperature Difference

MBL: Modelica Buildings Library

NIST: National Institute of Standards and Technology

NMBE: Normalized Mean Bias Error

PG: Propylene Glycol

PI : Proportional-Integral

SOC: State of Charge

Symbols:

$c_{i}$ : Charging coefficients

$d_{i}$ : Discharging coefficients
$H_{f}$ : Latent heat of fusion for water at $0{ }^{\circ} \mathrm{C}$

$\dot{m}$ : Mass flow rate of liquid

$m_{\text {ice }}$ : Ice mass in the tank

$P_{c h}$ : Charged fraction

$\dot{q}$ : Instantaneous heat transfer rate

$\dot{q}^{*}$ : Normalized instantaneous heat transfer rate

$Q_{s t o}:$ Total latent storage capacity

$T_{\text {in }}$ : Tank inlet temperature

$T_{\text {out }}:$ Tank outlet temperature

$T_{\text {fre }}$ : Freezing temperature of the water

$\Delta t$ : Timestep of the operation data used in the curve fitting

$\Delta T_{l m}:$ LMTD

$\Delta T_{l m}^{*}:$ Normalized LMTD

$\Delta T_{n o m}$ : Nominal temperature difference

\section{References}

Beckman, William A., Lars Broman, Alex Fiksel, Sanford A. Klein, Eva Lindberg, Mattias Schuler, and Jeff Thornton (1994). "TRNSYS The most complete solar energy system modeling and simulation software". In: Renewable energy, 5(1-4), pp.486-488. DOI: 10.1016/0960-1481(94)90420-0.

Braun, James E. (1990). "Reducing energy costs and peak electrical demand through optimal control of building thermal storage". In: ASHRAE transactions, 96(2), 876-888. URL: https://citeseerx.ist.psu.edu/viewdoc/download?doi=10.1.1.1 64.579\&rep $=$ rep $1 \&$ type $=$ pdf.

Candanedo, J. A., V. R. Dehkordi, and M. Stylianou (2013). "Model-based predictive control of an ice storage device in a building cooling system". In: Applied Energy, 111, pp.10321045. DOI: 10.1016/j.apenergy.2013.05.081.

Crawley, Drury B., Linda K. Lawrie, Frederick C. Winkelmann, Walter F. Buhl, Y. Joe Huang, Curtis O. Pedersen, Richard K. Strand et al. (2001). "EnergyPlus: creating a newgeneration building energy simulation program". In: Energy and buildings, 33(4), pp.319-331. DOI: 10.1016/S03787788(00)00114-6.

$\mathrm{Fu}$, Yangyang, Michael Wetter, and Wangda Zuo (2018). Modelica models for data center cooling systems. University of Colorado Boulder. URL: https://www.osti.gov/servlets/purl/1479111.

$\mathrm{Fu}$, Yangyang, Wangda Zuo, Michael Wetter, James W. VanGilder, and Peilin Yang (2019). "Equation-based objectoriented modeling and simulation of data center cooling systems". In: Energy and Buildings, 198, 503-519. DOI: 10.1016/j.enbuild.2019.06.037.

$\mathrm{Fu}$, Yangyang, Xing Lu, and Wangda Zuo (2019). "Modelica models for the control evaluations of chilled water system with waterside economizer". In: Proceedings of the 13th International Modelica Conference, Regensburg, Germany, March

4-6, 2019.URL:https://2019.international.conference.modelica.org /proceedings/html/papers/Modelica2019paperP09.pdf.

Guideline, A.S.H.R.A.E. (2014). Measurement of energy, demand, and water savings. ASHRAE Guidel 14-2014. URL: https://upgreengrade.ir/admin_panel/assets/images/books/A SHRAE\%20Guideline\%2014-2014.pdf.

Henze, Gregor P. and Jobst Schoenmann (2003). "Evaluation of reinforcement learning control for thermal energy storage systems". In: HVAC\&R Research, 9(3), 259-275. DOI: 10.1080/10789669.2003.10391069. 
Ihm, Pyeongchan, Moncef Krarti, and Gregor P. Henze (2004). "Development of a thermal energy storage model for EnergyPlus”. In: Energy and Buildings, 36(8), 807-814. DOI: 10.1016/j.enbuild.2004.01.021.

Jekel, Todd Bryant (1991). "Modeling of ice-storage systems". Master's thesis. University of Wisconsin-Madison, URL: https://minds.wisconsin.edu/bitstream/handle/1793/45602/Je kel1991.pdf?sequence=1.

Mattsson, Sven Erik, Hilding Elmqvist, and Martin Otter (1998). "Physical system modeling with Modelica". In: Control Engineering Practice, 6(4), 501-510. DOI: 10.1016/S09670661(98)00047-1.

Pertzborn, Amanda J. (2016). Intelligent Building Agents Laboratory: Hydronic System Design. US Department of Commerce, National Institute of Standards and Technology. URL:https://nvlpubs.nist.gov/nistpubs/TechnicalNotes/NIST. TN.1933.pdf.

Pradhan, Ojas, Amanda Pertzborn, Liang Zhang, and Jin Wen (2020). "Development and Validation of a Simulation Testbed for the Intelligent Building Agents Laboratory (IBAL) using TRNSYS". In: ASHRAE Transactions, 126, pp.458-466.

Strand, Richard Karl (1992). "Indirect ice storage system simulation". M.S. Thesis, Department of Mechanical and Industrial Engineering, University of Illinois at UrbanaChampaign.

Wetter, Michael (2011). "A View on Future Building System Modeling and Simulation". United States. URL: https://www.osti.gov/servlets/purl/1050665.

Wetter, Michael, Wangda Zuo, Thierry S. Nouidui, and Xiufeng Pang (2014). "Modelica buildings library". In: Journal of Building Performance Simulation, 7(4), pp.253-270. DOI: $\underline{10.1080 / 19401493.2013 .765506 .}$. 